\title{
Algo sobre Augusto ${ }^{1}$
}

Carlos Ávilai

há outras saídas?

certamente. quais, não sei. e ninguém sabe. cada um deve descobrir a sua.

A. de Campos ${ }^{2}$

Augusto de Campos é um dos mais importantes poetas brasileiros da segunda metade do século XX; faz parte de uma geração que nos deu, entre outros, Affonso Ávila, Décio Pignatari, Ferreira Gullar, Haroldo de Campos e Mário Faustino - todos com sólidas obras realizadas a partir dos anos 50 e de leitura imprescindível. Augusto continua em atividade (assim como Ávila, Pignatari e Gullar) e, recentemente, lançou mais uma coletânea de poemas: NÃO (SP, Perspectiva, 2003).

Todos os nomes citados acima estiveram, de alguma forma, envolvidos com a vanguarda (à exceção de Faustino, embora este também procurasse make it new à sua maneira, utilizando o verso e perseguindo o poema longo): participaram de movimentos, redigiram e assinaram manifestos, editaram publicações onde defenderam suas ideias, dialogaram entre si (às vezes, tomando caminhos diferentes; cf. a cisão concretismo/neoconcretismo), enfim, assumiram posições em relação à produção de poesia no país. Foi uma geração marcada pela busca do novo, pela experimentação e pela pesquisa.

1 Originalmente publicado em "SOBRE AUGUSTO DE CAMPOS", organização de Flora Sussekind, 2004, 7 Letras, Rio de Janeiro.

2 Carta de Augusto de Campos ao autor (28 de março de 1973). 
Com o passar do tempo esses poetas, que inicialmente mantinham um projeto coletivo de vanguarda, foram particularizando mais suas obras, dando ênfase a elementos pessoais que marcariam de forma definitiva suas poéticas. Embora todos mantivessem em suas produções um vivo interesse pela busca de novas formas de expressão, transitando por áreas diversas (realizando, por exemplo, experiências com a prosa - as Galáxias de Haroldo de Campos - ou com a colagem textual - as Barrocolagens de Affonso Ávila), a ênfase na posição de vanguarda foi sendo gradativamente superada.

Augusto de Campos se diferencia de seus pares nesse sentido. Mantém ainda os princípios de vanguarda que nortearam sua produção inicial, tanto em termos teóricos, quanto na prática poética. Ainda é em grande medida um "poeta concreto", mesmo que em alguns de seus poemas das últimas décadas tenha-se a impressão que o velho verso retorna, embora envolto numa coreografia gráfica peculiar, com cores e tipos variados.

Com a palavra, o próprio Augusto (que, é bom lembrar, sempre manteve postura crítica e distanciamento do pós-moderno e, até mesmo, da visão pós-utópica do irmão Haroldo):

"(...) pelo fato de não ter sido assimilada, senão em doses homeopáticas, a linguagem das vanguardas ainda não esgotou a sua dinâmica de realimentação da linguagem. Nesse sentido parece-me que as discussões em torno do chamado "pósmoderno" tendem a descambar, especialmente entre nós, para uma tentativa artificial e condenável de matar precocemente a vanguarda, pôr a modernidade entre parênteses, para recolocar a prática artística no leito acomodatício de um frouxo ecletismo, pretensamente não radical Atrás dessa (im)postura se esconde, entre outras, a fobia do tecnológico, marcada particularmente, nesta última quadra do século, pela informática. Aí está, realmente, o cerne da questão do "pós-moderno", palavra-ônibus com que se procura tamponar o vazio deste momento de transição, que prefiro ver sob a perspectiva do ultramoderno" ${ }^{3}$.

\footnotetext{
3 CAMPOS, Augusto de. "Morte e vida da vanguarda: a questão do novo". In: 30 Anos/Semana Nacional de Poesia de Vanguarda - 1963/93. Livro-catálogo do evento. Belo Horizonte, Secretaria Municipal de Cultura, 1993.
} 
Ultramoderno? Sim: invenção, experimentalismo, "verbivocovisual" etc. são (e, parece, continuarão sendo sempre) termos essenciais para Augusto. Sua produção poética se guia ainda por esses parâmetros. Ou seja, o poeta ainda insiste (e resiste) numa posição de vanguarda, que outros abandonaram em prol de projetos diferenciados. Sua visão da poesia ainda é tributária das aventuras inaugurais do concretismo e é ele o único dos três lançadores do movimento no Brasil que manteve uma postura coerente nesse aspecto (lembre-se que o último livro de Haroldo, $A$ Máquina do Mundo Repensada, é um retorno ao poema longo, ao verso metrificado no caso, o tradicional decassílabo - e rimado; lembre-se que Pignatari desinteressouse bastante da poesia, concreta ou não, e partiu para o conto, o romance e, mais recentemente, para o teatro, com seu Céu de Lona sobre Machado e Carolina, embora sempre dentro de um viés experimental semiótico).

Hoje, a poesia de Augusto vai além do livro, elevando a voltagem da linguagem concreta ao seu nível mais alto e imprevisível. Se Haroldo procurou uma saída na retomada do verso via passado poético (inclusive através das suas "transcriações"); se Pignatari voltou-se para o discurso verbal, violentando aqui e ali a sintaxe e a semântica; Augusto preferiu, mais uma vez, a radicalização - agora por meio da tecnologia: holografias, clip-poemas, poemas-lazer projetados nos espaços públicos, oralizações de textos em espetáculos multimídia e em CDs (Ouver, Poesia é Risco), animações poéticas em CD-Roms, site com poemas e traduções...

Depois de levar a poesia no suporte papel a um ponto-limite, desde Poetamenos (o conjunto de poemas coloridos, inspirado na "melodia de timbres" de Webern) até as composições visuais mais recentes dos volumes Despoesia e Não passando pelas colagens popcretas, pela poesia combinatória de Colidovescapo, pelos poemas-objeto de Poemóbiles e da duchampiana Caixa Preta (em parceria com Julio Plaza), e pelos poemas-cartaz do sofisticado álbum Expoemas - Augusto só poderia mesmo vislumbrar uma ampliação e abertura para sua produção através da tecnologia. Dessa forma acentuou o caráter visual que sempre marcou seu trabalho, acrescentando novos elementos aos poemas. Realizou em toda a plenitude o sonho inscrito no pórtico de Poetamenos: "luminosos, ou filmletras, quem os tivera!"; a postulação "verbivocovisual" contida no "plano piloto". 
Interessante observar que em meio a toda uma série de experiências formais e radicais com a linguagem essa poesia manteve linhas temáticas básicas, que já eram marcas da primeira produção de Augusto, ainda na fase verso (cf. O Rei Menos o Reino): angústia existencial; uma certa melancolia ou cicatristeza; crítica social: greve, luxo/lixo etc.; mudez (incomunicabilidade do ser); coraçãocabeça (tensão entre o sentir e o pensar); homenagens diversas; a própria poesia ("afazer de afasia"); a música etc. Trata-se de um construtivismo lírico, emoção contida externada em composições visuais que procuram equilibrar forma e conteúdo.

Interessante também ressaltar que essa é uma poesia do não verso, desde a experiência concreta (salvo um ou outro lance, como os Soneterapias 1 e 2, sonetos satíricos por excelência). Augusto não acredita na possibilidade ou na eficácia do verso? Parece que não, há muito tempo; sua poesia, pelo menos, deixa transparecer isso - embora, como já observamos, o velho verso soe ou ressoe em algumas linhas de suas composições: Pulsar, por exemplo, aproxima a digitalização da metrificação, num arranjo visual com planetas e estrelas. Outros exemplos poderiam ser apresentados. (Nesse sentido, Augusto seguiu direção contrária a de seu companheiro de geração Faustino, que não aceitava certas afirmações dos concretos, como aquela que dá por encerrado o "ciclo histórico do verso"; o autor de O Homem e sua Hora acreditava no verso e no poema longo: "Pretendo continuar criando, em poesia, com todo o arsenal léxico, com todas as partes do discurso, substantivando-as ou não. Para mim a verbalização, a imagem em movimento, o verbo, a imagem que está, é tão importante, poeticamente, quanto a imagem que é, o substantivo"4 ${ }^{4}$ )

Os pares contemporâneos de Augusto (Ávila, Gullar, Haroldo) ficaram mais no plano do verbal, utilizando ainda o verso ou também o não verso (cortes inusitados, fragmentação do discurso, linhas ou blocos assimétricos etc.), mas sem lançar mão da visualidade pura. Esta é uma marca forte do poeta paulista - marca, aliás, que o torna único. Augusto é quase um artista plástico (melhor, um artista gráfico), é um artesão da palavra explorada em todas as suas dimensões sígnicas, um designer do texto. Repetimos, é um caso único. A maioria da produção visual que se vê na cena poética brasileira, com raras exceções (um Sebastião Nunes, por ex.), não passa de mera

\footnotetext{
${ }^{4}$ Faustino, Mário. De Anchieta aos Concretos (Org. Maria Eugenia Boaventura). São Paulo, Companhia das Letras, 2003.
} 
diluição ou repetição dos processos e recursos expressivos do autor de Poemóbiles. O que há de mais criativo e instigante na nossa poesia atual segue trilha própria, sem ceder ao conservadorismo ou buscar referência apenas no concretismo.

Augusto é também quase um músico, sua aparelhagem sensível (ouvido sutil) e sua cultura musical aliadas ao seu domínio de verso, rima, ritmo e demais elementos da tradição poética (comprovado pelas suas excepcionais traduções de poetas em vários idiomas) possibilitaram uma produção onde a palavra e o som se ajustam à maravilha; seus poemas soam bem, parecem pedir música (além daquela que já está implícita na camada verbal), daí as várias composições eruditas (peças de Gilberto Mendes, Willy Corrêa de Oliveira etc.) e populares (Caetano Veloso e outros) já realizadas com seus textos. Afora isso, o próprio Augusto vem explorando a dimensão sonora de seus poemas através da oralização de vários deles em gravações e em apresentações públicas, em geral com a colaboração de Cid Campos. Ora, Poetamenos já apontava nessa direção; hoje, com os recursos modernos de gravação e reprodução, essa poesia encontrou seu habitat ideal.

As dimensões semântica (lirismo, crítica social, hommages a amigos e artistas, metalinguagem, "mensagens espaciais" etc.), sonora (palavra-som) e visual (design signíco no espaço branco; dinamismo de formas; movimento e cor) enformam a poesia de Augusto de Campos; poesia de pé no presente mas voltada ao futuro: o poeta acredita agora, com otimismo e alguma obsessão, nas possibilidades abertas pela informática, aproxima a poesia da tecnologia mas é também capaz de ironia crítica a esse respeito, como no poema final de seu livro Não, o anti-soneto Axel's site (onde parodia e atualiza a famosa fala do Axel de Villiers de L'Isle-Adam):

$$
\begin{aligned}
& \text { qua } \\
& \text { nto } \\
& \text { àpo } \\
& \text { esi } \\
& \text { aos } \\
& \text { com } \\
& \text { put }
\end{aligned}
$$


a d o

res

far

ã o i

S S O

por

nós

\begin{abstract}
'Nasceu em 1955, em Belo Horizonte (Minas Gerais), onde vive - é poeta e jornalista. Publicou os livros de poemas Aqui \& agora (1981), Sinal de menos (1989), Bissexto sentido (1999), Área de risco (2012) e Anexo de ecos (2017). Também publicou o volume de crítica Poesia pensada (2004) e um livro infantil: Bri Bri no canto do parque (2012). Foi editor do Suplemento Literário de Minas Gerais e participou de mais de vinte antologias no país e no exterior, entre elas, Nothing the sun could not explain - 20 Contemporary Brazilian Poets (Los Angeles/EUA, Sun \& Moon Press, 1997; $2^{\text {a }}$ edição: 2003). Seu poema "Mais uma vez" foi musicado por Gilberto Mendes e "Obstáculos" por Willy Corrêa de Oliveira. Ávila esteve presente em diversos encontros e seminários, trabalhou em televisão e editou publicações. Colabora em jornais, revistas impressas e on line. Segundo Haroldo de Campos, Ávila "se mostra capaz de pedra grossa e lavra fina. Construção rigorosa sensibilizada pela emoção; uma emoção que se filtra no constructo material das palavras como água de fonte em poros de rocha".
\end{abstract}

